\title{
Embedding Reading Promotion: The Paradigm Shift for Reading Promotion in Academic Libraries
}

\author{
Yuhan Zhang ${ }^{1, *}$ and Huan Tan ${ }^{2}$ \\ 1, 2 University of Electronic Science and Technology of China, Chengdu, 611731, China \\ ${ }^{1}$ yhzhang@uestc.edu.cn, ${ }^{2} 254368659 @ q q . c o m$ \\ *Corresponding author. Email: yhzhang@uestc.edu.cn
}

\begin{abstract}
The paper discusses the applicability of embedding theory in reading promotion, analyzes the advantages the academic libraries have for embedding, and points out that academic libraries can embed in 2 ways, upward into the macro system and downward into the micro environment respectively to let reading promotion become an indispensable part of the university and the students' life.
\end{abstract}

Keywords: Reading promotion, Embedding theory, Academic libraries.

\section{INTRODUCTION}

As an important force in library profession, academic libraries play an important part in reading promotion. According to the report by University Library Reading Promotion Committee, reading promotion mainly falls into the following forms, including reading essay competition, book promotion, book donation, knowledge competition, book drifting, book exhibition and film appreciation[1]. However, most of the activities are limited within the library. We can see the presence of readers and promoters, but not experts. Only a small number of readers participate. Sometimes students are forced to attend, arousing disgust. In this way, the libraries seem to act behind closed doors, just entertaining themselves.

Embedding theory is a core theory in new economic sociology, which is the theoretical basis for analyzing economic behavior, social work and other fields. Bases on the theory, the paper puts forward the idea of embedding reading promotion with a view to maximizing its service effect.

\section{EMBEDDING THEORY AND ITS APPLICABILITY IN READING PROMOTION}

Embedding theory is theory in new economic sociology. In 1944 Polanyi proposed the concept of embedding in his book Great Change [2]. Granovetter then developed this concept, believing that embedding is a universal social phenomenon. Economic activities are embedding not only in social networks, but also in politics, culture and religion [3].

Is embedding theory applicable in reading promotion? Theoretically, Xiaoyan Li states that reading promotion and social work are essentially in common, and have the possibility of integration [4]. Wang Li proposes that university library reading promotion can embed from 3 dimensions, including cognitive embedding, technological embedding and relational embedding [5]. In practice, reading promotion widely embeds into specific areas. The library of Shanxi University of Science and Technology embeds reading promotion into schools. The library of Guilin Normal College embeds into community and puts forward the mode of community plus platform [6]. The library of Xuzhou Institute of Technology includes reading promotion into education system of the institute [7]. Southwest Jiaotong University sets up a Reading and Writing Center, which coordinates teaching, activities, teachers and resources related to the promotion of classic reading within the whole university [8].

The above-mentioned practices can be divided into 3 categories. The first one is achieved by the power of other elements. It expands the content through Internet 
technology and space reconstruction and puts forward the modes like Internet plus reading promotion and Reading Promotion Embeds into Maker Spaces. This kind of embedding, in essence, is the further utilization of libraries's resources and the extension of reading promotion into physical space and virtual space, which is far away from the original meaning of embedding theory.

The second is equivalent to involving. In this way, librarians go out of the library and embed reading promotion into schools, communities and societies. We can see the presence of librarians in all the fields in which reading can be involved. This kind of embedding shortens the distance between readers and the library physically and virtually. .

The third type has the feature of integration. Reading promotion integrates itself into a more extensive system. For example, reading promotion goes beyond the library, integrates into higher-level platform and becomes a part of the university's teaching. This type is achieved via resource coordination, organization and integration with a view to building an interactive, collaborative development mode.

No matter whether it is involved or integrated, in the context of colleges and universities, what reading promotion faces is definite. They are the relevant departments of the university, such as Teaching Affair Department, Student Affair Department, Department of Propaganda, the schools and departments. To some extent, these departments are competitors. They all carry out activities similar to what reading promotion fulfills. Compared with the units, reading promotion is a new thing. As a part of the library service, reading promotion naturally has the characteristics of public welfare and non-marketization. A new, public welfare, non-market-oriented service embedding into the system is a rational and inevitable choice. However, when reading promotion attempts to embed into the system, the first thing we need to avoid is the suspicion, hindrance and exclusion of would-be embedded system. We need to avoid the negative image of redistribution of interests or proving the existence caused by imbedding.

Many papers have mentioned the significance of reading promotion. But we have to ask whether the existing system lacks necessary resources or capabilities, whether there are problems to be improved, and what kind of significance reading promotion service has for the existing system? It's obvious that the would-be embedded system has played the leading role in the university. Embedding reading promotion cannot be obtained by "belittling" the embedded objects. In the ideal state, the process of embedding is the process of integration, the process of effective interaction and integration of embedded subject and object, and the process in which both parties can benefit. But what are the advantages of reading promotion that can be accepted by embedded systems? We have to ask ourselves some questions: why does the other party want to merge with me? Why should I be embedded? Why cooperate with me? Why do you want to interact with me? What advantages does reading promotion have to improve its bargaining power in embedding.

\section{ANALYSIS OF ADVANTAGES FOR ACADEMIC LIBRARIES' READING PROMOTION}

First of all, university libraries have a variety of collections. Reading promotion is not a simple superposition of the library and reading promotion. The libraries should not only focus on reading promotion, but also be keen on using library resources to promote reading [9]. Massive collection resources are the premise and foundation for reading promotion.

Secondly, the advantage comes from the space reconstruction in recent years. In 1992, University of Iowa Library in the United States built the information arcade, which became the origin of global IC. Over the past 20 years, university libraries have realized transformation through space reconstructing. By way of adjusting the layout of the library, many university libraries design different types of spaces to meet the rapid demands for teaching and scientific research. Multiple spaces are offered, including virtual space, physical space, dynamic space, static space t. Information commons, study rooms, salon leisure areas, quiet learning areas and 24-hour learning areas are offered to meet the various learning needs of readers[10], making the library become the third space in the university campus for readers[11].

Besides, technical changes give reading promotion new connotation. We are now in the information age and digital age. New technologies are constantly emerging, including multimedia technology, big data analysis, interactive interface and so on. The adoption of VR as a learning tool allows readers promenade in virtual gallery of cultural exhibitions. The application of holography is used to display and recommend books, to involve readers in various reading activities. WeChat, blogs, forum, friends circle, Tiktok and other social apps serve as a platform for content production and exchange. Data analysis and data mining technology can help reading promotion be more tailored. In many university libraries, the use of data analysis has made annual reading reports a routine. In a word, tech-integrated has become a trend. Tech helps reading promotion embrace new service mode and tap into more possibility.

Based on the above-mentioned advantages, the paper comes to the following conclusions:

(1) Integrate collection with spaces, and launch activities with distinctive features. 
(2) The library should make full use of the technical means, find out the specific needs of different readers and put forward activities tailored to their needs.

(3) Embed reading promotion activities into user's physical and virtual environment to provide one-stop services

\section{PARADIGM SHIFT FOR READING PROMOTION IN ACADEMIC LIBRARIES}

Bases on the analysis, the paper puts forward that reading promotion in academic libraries can come to the following paradigm. That is, utilizing the principle of collaborative promotion, the library should embed upward into the macro system and downward into the micro environment.

\subsection{Embedding into Macro System}

Inheriting civilization and serving the society is the mission of library. To meet this demand, the library's reading promotion has developed from the previous spontaneous, partial, supplementary services to become the most dynamic and popular trend of the times. Colleges and universities bear the function of cultural inheritance and innovation. College students are the participants and creators of campus culture. The cultivation of cultural heritage and cultural confidence is a systematic project. Teaching, scientific research, practice, culture, network, psychology, management, service, funding and organization all have the function of educating people, which together constitute the education system of colleges and universities[12]. Integrating the reading promotion into the teaching system of the university will help remold the contemporary meaning of reading promotion, combine the mission of reading promotion with the goal of the university, make reading promotion embed into the system and become a part of the university's system so that its service tentacles extend to teaching and scientific research various aspects.

University libraries have unique advantages of collection and spaces over other departments. It can establish the reading promotion system including resource education, culture education, space education and curriculum education. Through technical means, the library's reading resources and services can be embedded into users' physical and virtual learning environment to provide whole process services.

The teaching system will, to some extent, have an impact on reading promotion, thus forming an "anti-embedding" force, prompting reading promotion to adjust and improve. In the end, the 2 parts will clarify their value on the basis of goal integration, and jointly promote and realize the collaborative goals. The two forces of "embeddedness" and "anti-embeddedness" interweave and interact with each other to form a new format, which penetrates downward and embeds into students' study and life through multi-level, multi-form and multi-channel activities.

\subsection{Embedding in Micro Environment}

Cultural heritage is a systematic project, which needs the cooperation of various departments, including schools and colleges, Students' Affair Department, Office of Educational Administration, and the Propaganda Department. For example, Big Reading and One book for One City are the result of joint participation and cooperation of libraries, education and art performance centers, schools and colleges, radio stations and other departments. Therefore, in addition to embedding into macro environment, it's necessary for university libraries to embed into micro environment so that reading promotion can become a part of students' study and life. Nowadays, information permeates into every field of the society, which means no single unit or department can undertake reading promotion alone [13]. Academic libraries should analyses differences for specific groups and put forward activities tailored to their demands. The key point is to utilize the application of technology, cooperate between groups and departments, interact between individuals, and seek joint promotion.

\section{CONCLUSION}

The goal for reading promotion is to inherit and disseminate culture. Embedding reading promotion integrates resources, blurs and weakens the traditional boundaries of the library, and embeds into the macro and micro environment of users' study and life. In this way, reading promotion will come beyond the physical space of the library and join seamlessly into the macro and micro environment of the university and students.

This paper is just a try into the combination between embedding theory and reading promotion. It theoretically discusses why to embed, whether it can be embedded and how to embed. In practice, it needs the further focus of librarians to go on with the study.

\section{REFERENCES}

[1] Questionnaire survey report on college students' reading and reading promotion in University Library

on http://www.lsc.org.cn/Attachment/Doc/132514548 8.pdf

[2] Karl Polany, Great change: the political and economic origin of our times. Zhejiang,2007

[3] Granovetter, M. The strength of weak ties, American Journal of Sociology. 78(1973)1360-80. 
[4] XiaoYan Li, Research on Library Reading Promotion Based on the Perspective of Social Work, Library theory and Practice. 12(2016) 35-37.

[5] Li WANG, Social Work Embedded in Reading Promotion of Academic Library, Library Research. 46(2016)51-54.

[6] Library holds reading promotion activities on https://tsg.glnc.edu.cn/info/1052/1258.htm.

[7] Xiaoling Wu, Zhen Wang, Analysis of Reading Promotion Work Embedded in Professional Culture Construction_-Taking the Library of Xuzhou University of Technology as an Example, Library Work and Study. 02(2019)108-112.

[8] Yun Liu, Fan Gao, Yong Yang, Ying Li, Embedded Promotion: An Effective Path to Classical Reading Promotion in University Libraries_-Taking Southwest Jiaotong University as an Example, Library and Information Service. 24(2018)104-109.
[9] Donglai Li, The Thinking of Library Reading Promotion, Library Tribune. 09(2018)114-118.

[10] Yaming Qiao, Xiaobo Xiao, A Framework of Study-centred Academic Library Space, The Library Journal of Shandong. 05(20175)67-70.

[11] Xiaobo Xiao, Yaming Qiao, Library Space: Planning and Utilization, Journal of Academic Libraries. 04(2014) 103-107.

[12] Zhengguang Zhang, On How to Create a Ten-dimensional Ideological and Political Education System. Journal of College Advisor, 04(2018)1-4.

[13] Piaosheng Wu, Thoughts on Reading Promotion Activity of University Library Based on Cultural Confidence, Library Work and Study. 05(2019)49-53. 